\title{
Infrastructure needs for electronic commerce and the Internet, intranets and extranets
}

\author{
C. Smith \\ Full-time student \\ Post Graduate Diploma in Information Management \\ RAU University \\ cath@ananzi.co.za
}

\section{Contents}

1. Introduction

2. Research problem

3. Internet infrastructure in the enterprise

4. Intranets in Cisco

5. Extranets in Cisco

6. Electronic commerce and its business potential

7. Conclusion

8. References

\section{Introduction}

Over the past decade, no innovation has impacted the way individuals and businesses communicate as dramatically as networking technologies. These technologies have enabled the low-cost development of open, interactive environments that help to break down the traditional barriers to strong business relationships. Many organizations are just discovering that the 'Internet and World-Wide Web (Web) offer an unparalleled opportunity for gaining competitive advantage in the global marketplace' (Cronin 1996).

The Internet is currently one of the most significant infrastructures in business. Its capacity for gathering information and the dissemination thereof is 'unsurpassed by any other current system in the world' (Van As 1998:4). For businesses, the Internet offers an excellent means to compete globally with other businesses of differing sizes. Now businesses in South Africa have the ability to market themselves in the global marketplace.

For many reasons, the Internet and Web is becoming a main arena for the business community worldwide. The Internet is both an enabling tool for business and the new business environment that is transforming the economy. According to Gascoyne and Ozcubukcu (1997:11), the Internet is the most global, borderless, cost-effective and open business application and communication infrastructure. Interactions and relationships 
between businesses and their customers have changed due to the Internet, as the Internet now allows customers many more choices.

The Internet has enabled businesses to change their strategic objectives. And 'for successful companies, the Internet is not about technology; its about the customer. Successful companies' Internet strategies are to deliver more value to the customer' (Gascoyne and Ozcubukcu 1997:11). The Internet's connective network enables organizations to establish closer links with not only their customers, but also with suppliers, partners, etc. by using intranets and extranets. It is only natural, with the advent of Internet technology throughout the world, that business should begin to use these networking facilities for both internal communication and with those outside the organization. Electronic commerce is the latest economic profiteer for businesses who have recognized this advent.

Cisco Systems is one company that has realized this and is in the process of establishing an intranet and extranet for the facilitation of improved e-commerce within the company. The company aims to be a more effective information distributor and allows employees a continuous and up-to-date means of attaining information, thus enabling continuous relationships with customers and partners.

\section{Research problem}

Can Cisco facilitate improved e-commerce within the company by using the infrastructure of the Internet alongside their intranet and extranet?

\section{Internet infrastructure in the enterprise}

As already established, the Internet has 'revolutionized the competitive business environment' (De and Mathew 1999). Companies across the globe are now being forced to change their strategies and use the Internet to increase performance. But in order to use the Internet sufficiently and ensure success, Cisco must have certain infrastructure and facilities in place.

\subsection{Internet strategy}

For Cisco to be successful in its utilization of the Internet, it must realize that the Internet is not about the technology; it is how to use the technology to ensure competitive advantage. According to Gascoyne and Ozcubukcu (1997:42), 'successful companies build their Internet business case by aligning their strategic business objectives, irrespective of any particular technology, with their Internet strategy'.

According to Van As (1998:84), a business that wants to embark on e-commerce must do proper planning: 'As with all other business ventures, a proper evaluation of the planned environment should be done, and business plans should be drawn up, which would align itself with the current business strategy.' Internal and any external infrastructures must be set up. Once Cisco management has decided on the strategy, the infrastructure planning and coordinating can begin.

\subsection{Architectural layout}

There are many ways in which Cisco can connect to the Internet. The main challenge is to find the best match between the type of service and the company needs (Cronin 1996:35). Firstly Cisco must decide on what network would suit the enterprise. The decision depends 
on factors such as geographical location, internal network topologies, etc. A company with a wide geographical network (e.g. Cape Town and Durban) would use a wide area network (WAN), while a company limited to one building would use a local area network (LAN).

Technology is the crucial driver and enabler of the business strategy. Network-centric computing and platform independent application development are enabling new technologies to strengthen the Internet feasibility in a company.

Network-centric computing allows a company, such as Cisco, to design and build its own business applications. It is best suited when there is an open, accessible network between businesses, clients, etc. These links are becoming available in many forms. This would be suitable for intranets within Cisco and of course an extranet with business clients and suppliers.

Platform independent tools such as Java is one application that can be used by all on the network regardless of their platform.

Certain technical components are needed alongside the hardware and software to ensure that the basic Internet architecture is met.

- Cisco must be connected to the Internet backbone, which is usually the Internet Service Provider (ISP) that connects the company either through a modem or an ISDN line to the Internet. The type of connection required depends on the amount of traffic within Cisco's system. The higher the amount of traffic, the larger the bandwidth should be for the company.

- Cisco must have an Internet Server. The server, according to Gascoyne and Ozcubukcu (1997:180), is the heart of the technical architecture, receiving requests from Internet users, retrieving the information locally or from networked devices, and replying. The server becomes vital in companies that have geographical distances to contend with. For example, communication within Cisco branches in Johannesburg and New York is directed through the server. There are two operating systems available to companies: UNIX-based platforms and Microsoft NT Intel platforms. Microsoft platforms generally cost less than UNIX, but the UNIX, according to Gascoyne and Ozcubukcu (1997:180), delivers a better performance.

- Internet server software selection is easy as most of the server software is based on industry standards.

- A database server, connected to a database system, directly affects the performance of the Internet. This helps with bottlenecks on heavily accessed sites.

- The e-mail server and gateway process e-mail requests from the Internet users and distribute the e-mail to the internal mailboxes.

- A firewall, according to Gascoyne and Ozcubukcu (1997:183), is a hardware and software connection that controls the traffic between Cisco's internal network and the public Internet: 'Firewalls stand as a barrier between an organization's Internet resources and the outside world. They are an organization's first line of defence against unauthorised Internet intruders.'

So now that the hardware has been described, the next step is to identify the basic software components required to access the Internet. According to Van As (1998:20) 'software is the application programs that run on the computer'. Most software is protocol based. A protocol is a rule that defines and enables computers to communicate, no matter what the server or operating system. For example

- TCP/IP

- HTTP (hypertext transfer protocol), the communication used to link information on 
the Web

- FTP

- Telnet

- Shareware, which is software that can be downloaded and used for a limited period. For the software to be used continuously, a nominal fee must be paid to allow the user to share the program with others (Kent 1994:44).

- Browsers, which are software programs that allow users to access a Web site and view the contents. Browsers such as Microsoft Internet Explorer and Netscape Navigator are the most popular.

\subsection{Management issues}

The most common problem with implementing Internet access and networks within an organization such as Cisco is badly formulated strategies that lead to failed Internet access facilitation. Far too often management look at the Internet in relation to the business as parts and not as a whole. Only certain elements of the Internet are incorporated into departments, such as e-mail and newsgroups, and not as an information-facilitating tool. Gascoyne and Ozcubukcu (1997:260) states: 'Once employees are active Internet users, they will locate and access a number of external information sources that are valuable for the whole company.'

There are numerous aspects that Cisco management needs to address in order to have a working Internet strategy. People, technology, information and the actual Internet process are a few issues management must address.

People within the organization are the most difficult issue for management to deal with. The main reason is people's fear of change, and many resist the change that the Internet will bring to an organization. Gascoyne and Ozcubukcu (1997:233) states that 'not everyone wants to be empowered. Not everyone wants to change. Not everyone understands the impact of the Internet'. Firstly, Cisco needs to foster information sharing and recognize and reward employees who do so.

Secondly there must be sufficient training within Cisco to ensure all users are familiar with the Internet and its uses for the business. A solid foundation of policies and training are very important to ensure a smooth Internet transition. Cronin (1996:265) believes that the 'essential step will highlight the company's priorities for the network use and help to avoid confusion about the how and why of the Internet'. There must be an effective training programme.

The next issue management faces is the technological one. Management must identify the correct components to ensure maximum use of the Internet to meet the company's actual needs. Technology is expensive, and so is the continuous upgrade and training requirements. Once specialists or the information technology (IT) department chooses the correct technology, the integration process can begin, that is the integration between the technology and the actual business processes. Depending on the size of the organization and how integral the Internet is to the business, assistance could be outsourced. If a company is large, it should have its own IT department.

There are many uses for the Internet within a business. According to Van As (1998:48), the following can increase business profitability:

- Effective communication about products and services within the organization and with customers through e-mail;

- establishing an interactive relationship with customers, keeping customers informed, serving customers faster and making it easier for customers to buy; 
- selling of products and services via a Web site; and

- introducing a knowledge and information sharing environment within the organization.

The Internet can help with information gathering and dissemination through newsgroups, search facilities, videoconferencing, etc. Management needs to make the organization aware of the abilities of the Internet and have the information and technology available to support the integration process.

\section{Intranets in Cisco}

A network is made up of hardware and software that link computers so that they can share data and processing responsibilities. More generally, a network connects individuals, groups, organizations and machines, thereby supporting intra- or inter-organizational data communications and fundamental business processes.

Organizations that have established a Web presence have realized that the same technology can be used to provide internal information services - 'hence the birth of the thing now being called an intranet' (Baines 1996). What the Internet has done for consumer communication, intranets are about to do for business.

An intranet is the application of Internet technology, more specifically World-Wide Web technology, within an organization. The proven Internet technology (Web servers, browsers, etc.) is applied, but 'access is restricted exclusively to organizational members for example by firewalls or physically separating the intranet from external networks (firebreaks)' (Damsgaard and Scheepers, 1999). The intranet enables Cisco to post internal information on a Web site that only those within Cisco can see. The intranet in Cisco is about communicating inside the organization.

The major benefit of the Internet's success is that it has finally forced the industry to adopt a single interface metaphor not controlled by any single entity - the World-Wide Web. It is that interface which is the heart of intranet creation. Baines (1996) states that the 'Internet/Web technology has entered the mainstream'. While the business industry currently is divided into Internet and non-Internet sectors, the open architecture of TCP/IP has caused an increased flooding in the number of products introduced by 'mainstream companies'. From a user's perspective, an intranet looks like the Internet and acts like the Internet. This is why many people, particularly younger employees within Cisco, can quickly adapt to intranet use. While an intranet is more limited in range as to what information is available, it is typically faster, more secure and generally more reliable than the Internet. These intranet advantages benefit users and the company.

An intranet in Cisco offers the possibility of increased productivity, lower costs, with faster delivery of products to the marketplace: 'Intranets are probably the most important new corporate computing platform since the introduction of the personal computer. They connect people to computers and people to people' (Hills 1998:4).

McGaughey (1999) and Damsgaard and Scheepers (1999) agree with the following characteristics of intranets, which allow their structure, combined with the Internet infrastructure in Cisco, to ensure improved performance within the actual organization:

- Intranet technology is multi-purpose and richly networked. Therefore intranets differ from other traditional intra-organizational information systems such as inventory 
systems, payroll systems, logistic systems, etc. These systems perform well-defined tasks and the interchange between various information systems is troublesome and limited to relative simple input and output operations. Intranet technology is the great unifier and it offers a way to integrate text, graphics, sound and video. Thus an intranet within Cisco can be regarded as an interactive medium for all employees because now employees can have internal information from departments as well as more visual-based information for customers.

- Intranet technology depends on supporting technologies such as communication protocols (specifically TCP/IP) and a physical network infrastructure. These must be in place before the technical set-up of intranet technology can take place. Hills (1998) states: 'Thereafter the technical installation is relatively straightforward.'

- Intranet technology differs radically from traditional IT in terms of its development. Baines (1996) states: 'Intranet development has no well-defined boundaries, functionality or time span, and it is not designed by experts, and, unlike the waterfall model used in traditional IS development, an intranet is emergent in nature.'

- Intranet technology has high network externalities. At first, when organizations had little access and few technologies available, few organizations were willing to use intranets. Now with the amazing capabilities that intranets offer to organizations, companies such as Cisco are more aware of the competitive advantage.

- Intranets may be implemented centrally in the organization as a corporate intranet, but units (such as divisions, departments or functional groups) can also implement the technology. In Cisco, all departments have their own departmental intranets, while the company has one central intranet, allowing for global information from the Cisco's across the world. Thus various 'levels' of intranets can coexist and the technology can be implemented simultaneously by a number of actors. The intranets within the individual departments are called 'Child Webs' with local content for specific users (with high and frequent interaction).

- An intranet can be regarded as fragile since it depends heavily on infrastructure, critical mass and network externalities. In this sense it is an 'all or nothing' type of technology.

\subsection{Facilitating cooperation to enhance competitiveness}

McGaughey (1999) states that 'cooperation is a cornerstone of agility. It is an important philosophical underpinning for agility'. Cooperation is necessary within an organization such as Cisco as a means of synchronizing the many people and departments that play a role in continually meeting ever-changing customer needs. The need for cooperation extends beyond the firm to customers, suppliers and stockholders.

Inter and intra-organizational cooperation requires the interaction of individuals and groups. 'Verbal or non-verbal communications is the primary driver of meaningful human interaction in and between organizations and, thus, communications is the key to cooperation' (McGaughey 1999).

It is the role of Internet technology in facilitating communications that makes it important in bringing about cooperation. Companies are using intranet capabilities to enhance intracompany communications and the Internet to support interaction with the rest of the world.

Cisco's intranet supports the sharing of information across departmental barriers and among geographically dispersed individuals and groups. De Mayaer (1997) states: 'The Internet makes possible the sharing of data or information among people, groups and organizations all over the globe.' The underlying infrastructure that supports the Internet and intranets allows information to be provided to those that need them, when they need them and in a form most useful to them. Since intranets and the Internet are based on a common infrastructure, information can be shared simultaneously within and outside an 
organization. Hills (1998:11) states: 'E-mail, for instance can be sent to targeted people within and outside an organization. Web page contents can be shared within an organization and with others across the globe. Audio and video conferencing as well as groupware products like Lotus Notes, can involve people from various areas of an organization and people from other organizations in collaborative work.'

The intranet within Cisco allows for new business opportunities to be generated, the end result being improved service to customers. As intranets allow companies such as Cisco to do things quicker, cheaper and better, the customer can only benefit. The intranet allows Cisco to publisize new information about products, such as videos, thus improving sales proactivity.

McGaughey (1999) illustrates how an intranet can facilitate cooperation to all employees within Cisco. He gives the example of a modification to a product design in response to changing customer needs. An intranet-based groupware product could facilitate the sharing of information regarding customer needs and collective interpretation of those needs, and it could support collaborative work on product and process design. A sales person familiar with the customer could provide input into the product design and simultaneously for process design. Participants could share the information about the customers' needs in an appropriate format to convey the relevant details and the product or process design. Such a capability could make it possible for anyone, anywhere in Cisco with intranet access to participate in the process of designing products and processes to better meet customer needs.

The above illustration focuses on intranet support for participation of individuals and groups within Cisco. Internet support enables Cisco to involve participants from other organizations in the process. McGaughey (1999) states: 'The customer, suppliers, consultants or virtually anyone with a stake in the process could be involved in the process. Internet support, providing some of the same capabilities discussed above, allows an organization to extend collaborative work beyond organizational boundaries.'

Cooperation requires communications. In some enterprises, such as Cisco, some cooperative arrangements may be steady, but others change as relationships and teams evolve to address the challenges of a changing world. The dynamic inter- and intraorganizational cooperation can only be sustained through a communications infrastructure that can support both stable and evolving relationships. Internet technology provides that infrastructure in Cisco.

\section{Extranets in Cisco}

A business such as Cisco has linked itself for the purpose of taking advantage of business opportunities beyond the reach of any one firm acting alone. Cisco can take advantage of 'business opportunities greater than the sum of the contributors' capabilities' (OneSoft Corporation 1998). Cisco has intensive, interactive relationships among participants that require sharing information within and among companies. Cisco has recently become part of the virtual business community. 'A virtual business is a seamless and borderless Web of companies' (McGaughey 1999). Therefore different companies, global or local, join forces to encourage competitive advantage. It is not practical to develop an entirely new information infrastructure every time membership changes, so Internet technology such as an extranet is an appropriate telecommunications infrastructure for supporting the virtual business. McGaughey (1999) states: 'As virtual business relationships change, Internet technology will allow former participants to be "unplugged" and new participants to be 
"plugged in"'.

With commerce-enabled extranets, companies such as Cisco are able to establish and maintain one-to-one relationships with their customers, other organizations, suppliers and employees at a very low cost through the Web and Internet infrastructure, thus offering a customizable and individualized 'experience that can be dynamically generated or modified, based on a user's privileges, preferences or usage patterns' (OneSoft Corporation 1998).

\subsection{Definition of an extranet}

So how does the intranet differ from the extranet? Many companies such as Cisco have attained significant business benefits from introducing intranets into the organization. Bayles (1998) believes that as organizations embrace e-commerce, many are now extending their intranets beyond the company boundaries to form extranets.

The extranet represents the bridge between the public Internet and the private corporate intranet. OneSoft Corporation (1998) states: 'The extranet connects multiple and diverse organizations on-line behind virtual firewalls, where those who share in trusted circles can network in order to achieve commerce-orientated objectives.' The extranet within Cisco will connect the intranets of the organization with its trading partners, suppliers, distributors and customers.

Another definition of an extranet is 'a permeable yet secure commerce-enabled network which electronically links distributed organizations or individuals over the Internet in a public, semi-public or private forum' (Bayles 1998).

A major driver of extranet growth is the universal adoption of the Internet protocol as a networking standard. According to Bayles (1998), many organizations are turning to extranets in preference to the proprietary networks required for Electronic Data Interchange (EDI) because Internet infrastructure is cheaper to install. Companies use extranets in the sharing of information. To keep up with the competition, most companies are continually looking for new and better ways to speed communications between trading partners, establish better relationships with customers, suppliers and partners, and reduce expenditures. The use of extranets can help businesses realize many of these goals. Vlosky, Fontenot and Blalock (2000) states: 'Extranets can facilitate the sharing of information, decrease operating costs, save time and resources, improve customer service, and generally improve business-to-business relationships.'

\subsection{Infrastructure of an extranet}

An extranet, according to Vlosky, Fontenot and Blalock (2000), should be seen as no more than an integrated software system, even though it is a very complex one. It is implemented with standard Internet technology and is relatively cheap and easy to set up. Bayles (1998) states: 'Where an intranet is already in place, extending it to an extranet is not too costly because all the hardware, software and network applications are already in place.'

The integration and coordination of a diverse and distributed group of business entities and individuals, each with potentially different networking and computing environments, require the commitment to an open systems platform that supports all standard protocols for information exchange. The Internet provides the ideal platform to fulfil these requirements, as it can support a wide range of data types for distributed information transfer.

The open standards of extranets help to resolve the problems faced by companies such as Cisco: information imprisoned within out-dated databases. 'The Web browser can provide a gateway into incompatible systems, thus allowing the organization's information to be drawn into the communication loop' (Bayles 1998). 
An extranet supported by 'powerful, commercial grade software applications' (OneSoft Corporation 1998), will serve Cisco and its enterprise community effectively and efficiently. Applications are the keys to any extranet's success and should meet the growing and changing demands of the user community.

Security is a very important characteristic possessed by an extranet in Cisco, as it serves multi-organizational interests. The architecture of the extranet must ensure that all participant and contributor content is protected within a secure and accountable structure that will enable system usability and dependability. Recent advancements in security technology provide extranet security that exceed the industry standards and thus protect all vital information.

\subsection{Extranets and customers}

The extranet creates a virtual marketplace with different trading processes from traditional commerce transactions. The extranet at Cisco can build stronger relationships with customers through 'collaborative customer service applications' (Bayles 1998). Customers can buy direct from a supplier, enter their own orders and track their transactions. The supplier can also benefit, as they are able to capture customer histories and information to ensure product development.

However Bayles (1998) warns businesses such as Cisco when moving from intranet to business-to-business extranets that it is more than just a technical linking of intranets. All business related through the extranet must be prepared content-wise and, of course, through the supply chain to ensure that business processes from product development to customer services are standardised and carefully integrated.

\section{Electronic commerce and its business potential}

The Internet has done more than just allow buying and selling on-line; it has created a whole new way of structuring business. Among the most effective tools for success in the new world of electronic commerce are collaboration and involvement (Bressler and Grantham 2000:33). Karakaya and Charlton (2001) indicate that businesses develop three major types of Web sites:

- Informational Webs that are dedicated to disseminate information;

- transactional Webs that support activities which ultimately result in the transfer of an entity of intrinsic (usually monetary)value; and

- operational Webs that offer new mechanisms for conducting business operations by integrating computing power, human intelligence and other relevant resources. The use and development of the operational Webs are currently increasing dramatically because of security issues.

Furthermore, companies are attempting to share their knowledge based information systems and other related resources among their partners and their employees. This and the security issues have pressured many firms to develop intranets and extranets. Intranets and extranets within Cisco are designed to create strategic partnerships between the company and its employees, suppliers, distributors and retailers.

\subsection{Definition of e-commerce}

In 1995, e-commerce was defined as 'the buying and selling of goods and services using electronic media' (Bressler and Grantham 2000:83). Today a more accurate definition is 'the innovative use of the Internet to establish, facilitate and augment spontaneous commercial 
relationships between many buyers and sellers' (Cronin 1996:54).

\subsection{Types of e-commerce}

E-commerce based on the Internet extends the reach of sellers and buyers. It provides both with more information and makes markets more international. Since its beginnings, ecommerce was quickly evolved into different types of activities. Probably the first and simplest activity was the 'commercial interaction between informal market-organized individual agents, offering goods and services to each other. This informal market may be termed a "public flea market", which in the Internet sometimes takes the form of a simple "chat site" where messages are regularly posted with the e-mail address of the seller' (Murillo 2001). This form of activity has now been termed consumer-to-consumer (C2C).

A next stage is the consumer-to-business (C2B) one, in which consumers convey their bids for goods and services to an organized marketplace, which may be characterized by auctioneers. The auctioneers offer their merchandise in attractive Web sites, but the consumer decides not only on which wares to buy but also on the price to pay. With the arrival of e-commerce, the customer has gained far more control over price, availability and preference. Customers can now decide how, why and where they will make their purchase. Gascoyne and Ozcubukcu (1997:19) states: 'The key to ensuring e-commerce works for the companies is to anticipate the Internet's impact on customers habits, decision making patterns, needs, interests and expectations.'

Murillo (2001) states: 'Probably the most sophisticated form of e-commerce and the one which needs the most developed institutional, commercial, technological and transportation infrastructure, is that in which the interacting direction goes from business to business, or $\mathrm{B} 2 \mathrm{~B}$, and from business to consumer, or B2C.' Internet technology generated the first wave of e-commerce in the new business economy. Businesses using the Internet for e-commerce facilitation must realize that now they have the ability to reach a global market, they must attract and maintain those customers. Melewar and Navalekar (2002) states: 'The emergence of e-Commerce has the potential of freeing industries and businesses from their geographical moorings giving rise to new rules of competition.'

Cisco's e-commerce strategy is the Cisco Connection Online (CCO), which is the name of the site that houses all of Cisco's Internet resources. The two main functions performed by the site are service or support and sales. Through links to other sites, the CCO provides registered customers and employees with open access to the company's resources and systems, which include product and technical information, customer service, technical support, software downloads and ordering applications. According to Chris Stinton, director of Cisco Connection, the company's objective is 'straightforward: to streamline business processes and speed up access to critical information and services' (Klineberg 1998:211).

\subsection{Cisco's service and support}

The use of Web-based applications through the company's Web site and intranet via the Internet has allowed for a range of customer self-service solutions that would not be possible via traditional customer-supplier interactions. The CCO has allowed the company to change its relationships with its customers through the infrastructure of the networked environment. One hub available within the CCO network is the Technical Assistance Library, where users get on-line answers to technical questions and manage cases without having to call the support centre.

\subsection{Cisco's sales}

E-commerce takes advantage of the Internet's low cost of connectivity and the network capabilities to simplify and automate many daily selling tasks of the business. The CCO's e- 
commerce engine is the Internetworking Products Centre (IPC). The IPC allows customers and partners to price and submit electronic orders for over 12800 Cisco products and parts. Klineberg (1998:213) states: 'As of November 1997, 32\% of all Cisco transactions were being conducted online, representing $\$ 5$ million a day in revenues.'

\subsection{Future of the Internet and e-commerce}

Businesses and consumers will continue to use the Internet for more reasons than ever. As we have seen the emergence of new businesses, such as search engines, auction houses and travel sites, many more new businesses will be created. Bandwidth, which for many years has been the greatest barrier to Internet development, is expanding. High-speed access via digital fiber optic network or satellite, supported by advanced digital compression technology, will become commonplace. Real-time communication and feedback is now possible, but will become widespread in the near future.

The use of EDI by businesses will eventually fade away: 'Customer databases will be connected to vendor databases, placing orders and using artificial intelligence software to lower or increase prices based on demand and supply as well user input data' (Karakaya and Charlton 2001).

Security is of course still a main concern, not only to businesses but also to consumers: 'To date, only one component of e-commerce transactions has gained recognition and development: secure transaction protocol' (Ghosh 1998:3). While secure transaction protocols are essential for privacy of information in transactions, they are not sufficient enough to secure e-commerce transactions. All four major components of software (clientside software, data transaction protocols, Web server software, and network server operating system software) that are used to handle e-commerce transactions over the Internet must be equally secured.

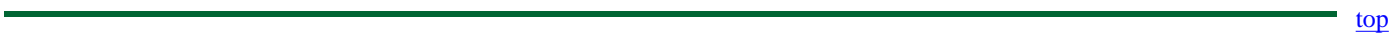

\section{Conclusion}

Internet technology can assist firms such as Cisco in their efforts to achieve a competitive advantage. Internet technology helps to enrich customers in a variety of ways from monitoring customer needs to better supporting customer processes. Internet technology provides the communications infrastructure that enables communications, in a variety of forms and formats, among individuals, groups and organizations to facilitate the intra- and inter-organizational cooperation necessary to achieve competitive advantage.

Internet technology provides a flexible communications infrastructure that can support the constantly changing intra- and inter-organizational relationships that are necessary for success in an environment of rapid change. McGaughey (1999) states: 'Internet technology leverages the impact of people and information. The value of information is leveraged when it is available to those that need it, when they need it, where they need it and in a form useful to them. People are leveraged when they are empowered with the knowledge and information they need to make decisions and perform job-related tasks.'

Internet technology provides the vehicle for delivering information and for delivery of education and training that expands the knowledge of workers, both of which help to empower individuals and groups to act in ways that contribute to competitive advantage.

The use of Internet and e-commerce by businesses around the world is now a way of doing business. The Internet is not just another medium or a distribution channel to reach customers. It is an important medium to find new customers and continue relationships with 
current customers. It is almost impossible for businesses and consumers to ignore this new technology and the advent of intranets and extranets.

Most companies see the Internet and e-commerce as a new opportunity. The use of intranets and extranets, alongside the technology and infrastructure the Internet provides, is sure to improve the way businesses such as Cisco operate. Cisco has been involved in e-commerce since 1997. The rapid increase in the number of electronic transactions over their extranet can only prove that the infrastructure provided by the Internet to the company's intranet and extranet is definitely facilitating improved e-commerce for the company.

\section{References}

Baines, A. 1996. Intranets. Work study 45(5):5-7.

Bayles, D. 1998. From intranet to extranet: bringing customers and suppliers into the loop. The Antidote 24(3):32-33.

Bressler, S. and Grantham, C. 2000. Communities of commerce. New York: McGraw-Hill.

Cronin, M. 1996. Doing more business on the Internet. New York: Van Nostrand Reinhold.

Damsgaard, J. and Scheepers, R. 1999. Power, influence and intranet implementation. Internet technology and people 12(4):333-358.

De, R. and Mathew, B. 1999. Issues in management of Web technologies: a conceptual framework. International journal of information management 19:427-447.

De Mayaer, D. 1997. Internet's information highway potential. Internet research: electronic networking applications and policy 7(4):287-300.

Gascoyne, R. and Ozcubukcu, K. 1997. Corporate Internet planning. New York: Van Nostrand Reinhold.

Ghosh, A.K. 1998. E-commerce security: weak links, best defences. New York: Wiley Computer Publishing.

Hills, M. 1998. The definition and dynamics of intranets. In: Lloyd, P. and Boyle, P. Webweaving: intranets, extranets and strategic alliances. Johannesburg: Butterworth Heinemann

Karakaya, F. and Charlton, E.T. 2001. Electronic commerce: current and future practices. Managerial finance 27(7):42-53.

Kent, P. 1994. The Idiot's guide to the Internet. Indianapolis: QUE.

Klineberg, A.M. 1998. Electronic commerce at Cisco systems. In: Lloyd, P. and Boyle, P. Web-weaving: intranets, extranets and strategic alliances. Johannesburg: Butterworth Heinemann.

McGaughey, R.E. 1999. Internet technology: contributing to agility in the twenty-first century. 1(1):7-13. 
Melewar, T. and Navalekar, A. 2002. Leveraging corporate identity in the digital age. Marketing intelligence and planning 20(2):96-103.

Murillo, L. 2001. Supply chain management and the international dissemination of ecommerce. Industrial management and data systems 101(7):370-377.

OneSoft Coporation. 1998. The extranet solution. In: Lloyd, P. and Boyle, P. Web-weaving: intranets, extranets and strategic alliances. Johannesburg: Butterworth Heinemann

Van As, B. 1998. The Internet as a strategic business management tool. Master's thesis: Rand Afrikaans University. (Unpublished).

Vlosky, R.P., Fontenot, R. and Blalock, L. 2000. Extranets: impacts on business practices and relationships. Journal of business and industrial marketing 15(6):438-457.

\section{Disclaimer}

Articles published in SAJIM are the opinions of the authors and do not necessarily reflect the opinion of the Editor, Board, Publisher, Webmaster or the Rand Afrikaans University. The user hereby waives any claim he/she/they may have or acquire against the publisher, its suppliers, licensees and sub licensees and indemnifies all said persons from any claims, lawsuits, proceedings, costs, special, incidental, consequential or indirect damages, including damages for loss of profits, loss of business or downtime arising out of or relating to the user's use of the Website. 
ISSN 1560-683X

Published by InterWord Communications for the Centre for Research in Web-based Applications, Rand Afrikaans University 